CLINICAL STUDY

\title{
Characterisation of DEHAL1 expression in thyroid pathologies
}

Kerstin Krause*, Stefan Karger*, Oliver Gimm ${ }^{1}$, Sien-Yi Sheu ${ }^{2}$, Henning Dralle ${ }^{1}$, Andrea Tannapfel ${ }^{3}$, Kurt Werner Schmid ${ }^{2}$, Corinne Dupuy ${ }^{4}$ and Dagmar Fuhrer

III. Medical Department, University of Leipzig, Ph.-Rosenthal-Str. 27, 04103 Leipzig, Germany, ${ }^{1}$ Department of Surgery, University of Halle, Halle, Germany, ${ }^{2}$ Institute of Pathology and Neuropathology, University of Duisburg-Essen, Essen, Germany, ${ }^{3}$ Institute of Pathology, University of Bochum, Bochum, Germany and ${ }^{4}$ Unité 486 Inserm, Université Paris 11, 92296 Châtenay-Malabry, Cedex, France

(Correspondence should be addressed to D Fuhrer; Email: fued@medizin.uni-leipzig.de)

*K Krause and S Karger contributed equally to this work

\begin{abstract}
Iodotyrosine dehalogenase 1 (DEHAL1) is a transmembrane protein involved in the recycling of iodide in the human thyroid. The aim of the present study was (I) to investigate whether DEHAL1 expression is different in differentially functioning thyroid pathologies and (II) to evaluate DEHAL1 as a possible marker of thyroid cell differentiation.

Design and methods: Real-time PCR for DEHAL1 and its isoform DEHAL1B was performed in a series of 105 thyroid specimens, including toxic thyroid nodules (TTN), Graves' disease (GD) thyroids, benign cold thyroid nodules (CTN), normal thyroid tissues and thyroid cancers (follicular thyroid carcinomas (FTC), papillary thyroid carcinomas (PTC), partially differentiated thyroid cancers (PDTC) and anaplastic thyroid carcinomas (ATC)). In addition, DEHAL1 protein expression was studied by immunohistochemistry in 163 benign and malignant thyroid pathologies and normal thyroids.

Results: (I) The highest DEHAL1 mRNA levels were found in GD thyroids, while downregulation of DEHAL1 and DEHAL1B mRNA occurred in PTC and ATC $(P<0.001$ and $<0.05$ respectively); (II) DEHAL1 protein was overexpressed in TTNs and GD thyroids with predominant apical staining in all samples; (III) a weaker and patchy staining pattern was found in CTNs and normal thyroids; (IV) in differentiated thyroid cancers (FTC and PTC), a diffuse cytoplasmic DEHAL1 expression was found; and (V) in PDTC and ATC, DEHAL1 expression was faint or absent.

Conclusion: Upregulation of DEHAL1 protein expression and sublocalisation of DEHAL1 at the apical cell pole in TTNs and GD thyroids is consistent with increased thyroid hormone turnover during thyrotoxicosis. Diffuse cytoplasmatic localisation or downregulation of DEHAL1 expression in thyroid cancers suggests alteration or loss of DEHAL1 function during thyroid cell dedifferentiation.
\end{abstract}

European Journal of Endocrinology 156 295-301

\section{Introduction}

Iodotyrosine dehalogenase 1 (DEHAL1) has been identified as a thyroid protein with a putative molecular size of $33 \mathrm{kDa}(1-4)$.

The DEHAL1 is involved in the NADPH-dependent deiodination of the free mono-iodotyrosines (MIT) and di-iodotyrosines (DIT), which are released along with the thyroid hormones T4 and T3 through thyroglobulin proteolysis. DEHAL1 action on DIT and MIT results in the liberation of iodide and tyrosine, which can be reused for thyroid hormone synthesis.

The gene coding DEHAL1 has recently been cloned and is localised on chromosome 6 (6q24-25) (5). Besides the thyroid, DEHAL1 mRNA has been found in human kidney and liver tissue, albeit at lower expression levels. In addition, a variant gene product termed DEHAL1B has been described, which differs from the DEHAL1 isoform by a $102 \mathrm{bp}$ insertion and is assumed to be functionally inactive $(4,5)$.

Gnidehou et al. (4) recently described first structural and functional properties of DEHAL1. They proposed that it constitutes a transmembrane protein with a large extracellular N-terminus containing most of the nitroreductase domain, a single transmembrane segment and a short intracellular C-terminus. Furthermore, they suggested that DEHAL1-catalysed deiodination takes place at the apical membrane in close proximity to the thyroglobulin iodination site. DEHAL1 mRNA expression is upregulated by cAMP, which implies that DEHAL1 along with the sodiumiodide symporter (NIS), thyroid peroxidase (TPO) and thyroglobulin (TG) may represent a marker of differentiated thyroid function.

Since intrathyroidal iodine metabolism is known to vary considerably between the euthyroid and 
hyperthyroid state as well as in thyroid pathologies with different functional properties, e.g. toxic and cold thyroid nodules $(6,7)$, we asked to what extent this may be reflected by differences in DEHAL1 expression. Furthermore, we asked whether DEHAL1 expression was altered with ongoing thyroid dedifferentiation.

\section{Materials and methods}

\section{Thyroid samples}

A total of 16 benign cold thyroid nodules (CTN; 6 colloid nodules and 10 follicular adenomas), 10 toxic thyroid nodules (TTN; 7 colloid nodules and 3 follicular adenomas), 26 surrounding normal thyroid tissues (STs) of the same patients, 8 Graves' disease (GD) thyroids, 21 follicular thyroid carcinomas (FTC), 18 papillary thyroid carcinomas (PTC) and 6 anaplastic thyroid carcinomas (ATC) were studied for DEHAL1 and DEHAL1B mRNA expression.

In addition, paraffin-embedded tissue sections of 163 thyroid specimens (partially including the samples analysed for mRNA expression) were used for immunohistochemical studies. These comprised $16 \mathrm{CTN}$ and 11 TTNs with corresponding normal tissues, 5 GD, 8 FTC, 63 PTC (17 follicular variant PTC, 13 conventional PTC and 34 tall cell variant PTC), 22 partially differentiated thyroid cancers (PDTC), 6 ATC samples and 5 medullary thyroid cancers (MTC; negative controls).

Thyroid samples were obtained from the Department of Surgery, Martin-Luther-University of Halle, Germany, local Leipzig hospitals and the Department of Pathology and Neuropathology, University Hospital of Essen, Germany. Thyroid samples were selected by corresponding results for ultrasound, scintiscan and histology as described $(8,9)$. Patients with TTN or GD received antithyroid medication and had euthyroid function or subclinical hyperthyroidism at time of surgery. Patients with CTNs, FTC, PTC and ATC did not receive thyroid medication and were euthyroid at time of surgery. Informed consent was obtained from all patients. The local ethics committee approved the study.

\section{RNA extraction and RT-PCR}

Snap frozen tissue samples were pulverised and transferred into TRIzol reagent (Invitrogen) for RNA extraction. RNA cleanup was performed using the RNeasy Mini Kit 50 (Qiagen Sciences). cDNA synthesis was performed at $37^{\circ} \mathrm{C}$ for $60 \mathrm{~min}$ with $1 \mu \mathrm{g}$ RNA using random hexamer primers (Promega) and Moloney murine leukemia virus reverse transcriptase (Invitrogen). Consistent expression of housekeeping genes $(\beta$-actin $(A C T B)$ and $G A P D))$ was demonstrated in all samples by RT-PCR as described $(8,9)$.

\section{Real-time PCR}

Real-time PCR was performed using the LightCycler System and LightCycler-DNA Master SYBR Green I Kit (Roche) according to the manufacturers' instructions: annealing temperatures and $\mathrm{MgCl}_{2}$ concentrations were optimised to create a one-peak-melting curve. The following intron-spanning sense and antisense primers were used:

DEHAL1 : forward : 5'-TTT CCT GAC TCC CAT CTT GG-3' reverse : 5'-TGC CAT TCA TCA GCA TCT TC-3'

DEHAL1B : forward : 5'-TCA CCA TGC GGC ATC AGA CT-3 reverse : 5'-CCA AGA GGA GCA GGC GAG AGG-3'

After initial denaturation $(30 \mathrm{~s})$ at $95{ }^{\circ} \mathrm{C}$, PCR was carried out for 40 cycles $\left(95{ }^{\circ} \mathrm{C}\right.$ for $0 \mathrm{~s}, 64{ }^{\circ} \mathrm{C}$ for $7 \mathrm{~s}$ and $72{ }^{\circ} \mathrm{C}$ for $27 \mathrm{~s}, 4 \mathrm{mM} \mathrm{MgCl} 2$ ) for DEHAL1 and for 40 cycles $\left(95{ }^{\circ} \mathrm{C}\right.$ for $0 \mathrm{~s}, 62{ }^{\circ} \mathrm{C}$ for $7 \mathrm{~s}$ and $62{ }^{\circ} \mathrm{C}$ for $27 \mathrm{~s}, 4 \mathrm{mM} \mathrm{MgCl}_{2}$ ) for DEHAL1B. The LightCycler software calculated the threshold cycles. Each sample was measured in duplicates and real-time PCR was repeated at least once. The fold difference $(n)$ in upregulation or downregulation of mRNA expression was calculated as follows:

$\begin{aligned} n= & 2^{\text {(threshold cycle gene (NT)-threshold cycle gene diseased tissues (DT)) } /} \\ & 2^{((\mathrm{ACTB} \text { (NT)-of ACTB (DT)) }}\end{aligned}$

'Normal tissue' corresponds to the surrounding tissue of toxic thyroid nodules (for TTN and GD) and cold thyroid nodules (for CTN, FTC, PTC and ATC) respectively. The Mann-Whitney $U$-test within the SPSS software version 11.5 was used for statistical analysis.

\section{Immunohistochemistry}

Paraffin embedded sections $(3 \mu \mathrm{m})$ were dewaxed and rehydrated. Subsequently, sections were pretreated in a microwave oven in $0.1 \mathrm{M}$ citrate buffer ( $\mathrm{pH} \mathrm{6)}$ ) for one cycle at $750 \mathrm{~W}$ for $3 \mathrm{~min}$ and for 4 cycles of $3 \mathrm{~min}$ at $350 \mathrm{~W}$. The LSAB + System (DAKO Cytomation; Hamburg, Germany) was used for immunodetection. Briefly, slides were incubated with $3 \% \mathrm{H}_{2} \mathrm{O}_{2}$ for $30 \mathrm{~min}$ followed by three wash steps with PBS/1\% BSA. Unspecific binding was blocked for $30 \mathrm{~min}$, and slides were incubated with a polyclonal DEHAL1-specific antibody as previously described (4). Immunoreactivity was demonstrated using a biotinylated secondary antirabbit antibody, streptavidin peroxidase and diaminobenzidin. Sections were counterstained with hemalaun and mounted in Aquatex (Merck). Semiquantitative analysis of DEHAL1 staining was done by three 
Table 1 Median mRNA expression levels for DEHAL1 and $D E H A L 1 B$ in different thyroid pathologies.

\begin{tabular}{lcc}
\hline Samples & DEHAL1 & DEHAL1B \\
\hline Graves' disease (GD, $n=8)$ & 2.08 & 0.95 \\
Toxic thyroid nodule (TTN, $n=10)$ & 1.36 & 0.70 \\
Surrounding tissue of TTN (stTTN, $n=10)$ & 0.99 & 0.86 \\
Cold thyroid nodule (CTN, $n=16$ ) & 1.71 & 2.99 \\
Surrounding tissue of CTN (stCTN, $n=16)$ & 0.84 & 0.70 \\
Follicular thyroid carcinoma (FTC, $n=21)$ & 0.83 & 1.04 \\
Papillary thyroid carcinoma (PTC, $n=18$ ) & $0.26^{\star}$ & $0.06^{\star}$ \\
Anaplastic thyroid carcinoma (ATC, $n=6)$ & $0.05^{\dagger}$ & $0.06^{\dagger}$
\end{tabular}

Results show fold upregulation (median) of DEHAL1 and DEHAL1B expression in thyroid pathologies compared to normal thyroid tissues (stTTN for TTN and GD; stCTN for CTN, FTC, PTC and ATC). *Significant differences in DEHAL1 and DEHAL1B expression were found in PTCs $(P<0.003$ and $P<0.0001$ respectively $)$ and ${ }^{\dagger}$ ATCs $(P<0.001$ and $P<0.05$ respectively; Mann-Whitney $U$-test) compared with all other thyroid specimen.

independent investigators (S K/S Y S/D F) by determining the percentage of positively stained thyrocytes/six randomly selected sections/slide $(200 \times$ magnification) and quantified as follows: - no staining;,$+<30 \%$ staining;,$++ 30-60 \%$ staining; ,$+++>60 \%$ staining.

\section{Results}

\section{Analysis of DEHAL1 and DEHAL1B MRNA expression in thyroid pathologies}

DEHAL1 gene expression was detected in all thyroid tissue samples (Table 1; Fig. 1A). The highest DEHAL1 mRNA levels were found in GD thyroids. Both TTN and CTN showed higher median DEHAL1 mRNA levels in comparison with the surrounding normal tissues (ST), but this did not reach statistical significance (Fig. 1A). There was no difference in DEHAL1 mRNA expression between the ST of CTN and TTN. Downregulation of DEHAL1 mRNA was found in PTCs $(P<0.003)$ and ATCs $(P<0.001$; Table 1; Fig. 1A).
We then asked whether these changes in DEHAL1 mRNA expression could be due to altered splicing. In CTN and FTC, we found an upregulation of the DEHAL isoform 1B reaching significance $(P<0.001)$ for CTNs (Table 1, Fig. 1B), while DEHAL1B was unchanged in the hyperfunctional tissues and their ST. In PTC and ATC, DEHAL1B was downregulated or absent $(P<0.0001$ and $P<0.05$; Table 1; Fig. 1B).

\section{Analysis of DEHAL1 protein expression in thyroid pathologies}

Immunohistochemical analysis showed a very strong, uniform DEHAL1 staining at the apical pole in all GD thyroids and TTN samples (Figs 2A and B and 4A). A much weaker cytoplasmic staining pattern, predominantly found in small follicles, was observed in CTN (Fig. 2D) and all STs (Figs 2C and E and 4A). There were no differences in DEHAL1 staining intensity between the ST of TTN and CTN. A diffuse cytoplasmatic staining pattern of variable intensity (weak to strong, Fig. 4A) was found in FTC (Fig. 2F) and PTC (Fig. 2G). No significant differences were detected for PTC subtypes (follicular, tall cell and conventional PTC, Fig. 4B). In partially differentiated and undifferentiated thyroid cancers, DEHAL1 protein expression was weak (9/22 PDTC) or absent (13/22 PDTC; Fig. 3B, all ATC; Fig. 2H). No DEHAL1 protein expression was detected in five medullary thyroid cancers, which were used as negative controls (Fig. 2I). Results of the semiquantitative analysis of DEHAL1 protein expression (relative distribution of staining/thyroid specimen in different subgroups) are shown in Fig. $4 \mathrm{~A}$ and $\mathrm{B}$.

\section{Discussion}

In order to investigate a possible alteration in the expression of iodotyrosine dehalogenase 1 due to
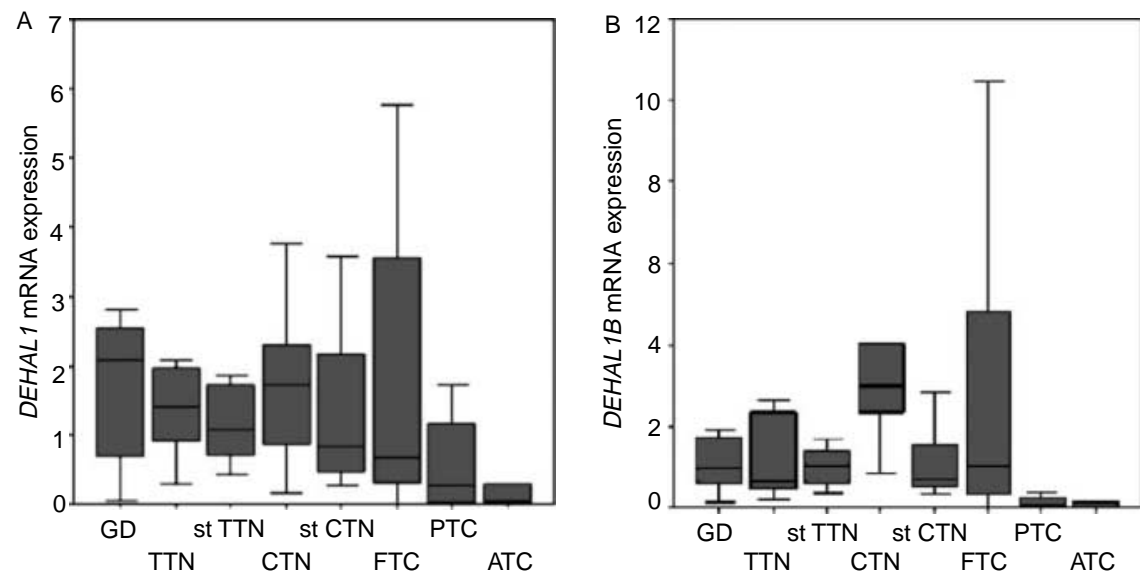

Figure 1 Expression of DEHAL1 and $D E H A L 1 B$ mRNA in different thyroid pathologies. Box plots showing median and distribution (box area $=50 \%$ of samples) of DEHAL1 mRNA expression (A) and DEHAL1B mRNA expression (B) in different thyroid pathologies and normal thyroid tissues, normalised for ACTB expression. GD, Graves' disease; TTN, toxic thyroid nodule and stTTN, corresponding normal thyroid tissue of same patient; CTN, cold thyroid nodule and stCTN, corresponding normal thyroid tissue of same patient; FTC, follicular thyroid carcinoma; PTC, papillary thyroid carcinoma and ATC, anaplastic thyroid carcinoma (see Table 1). 
A

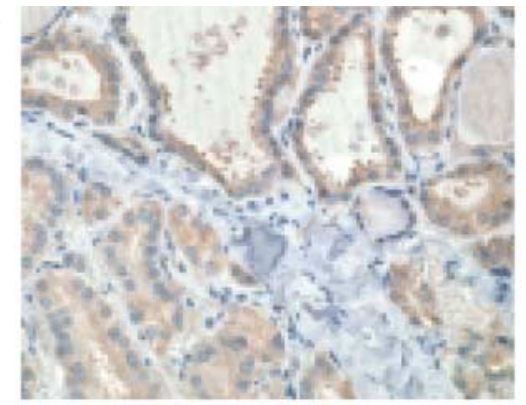

B

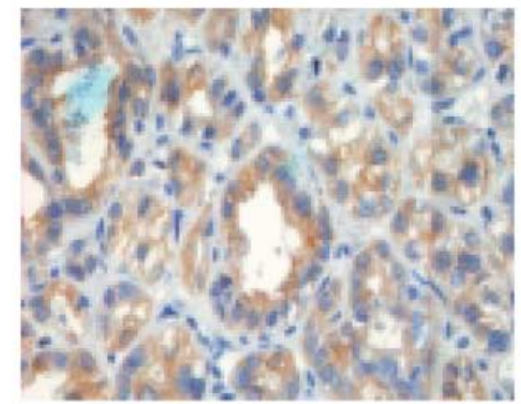

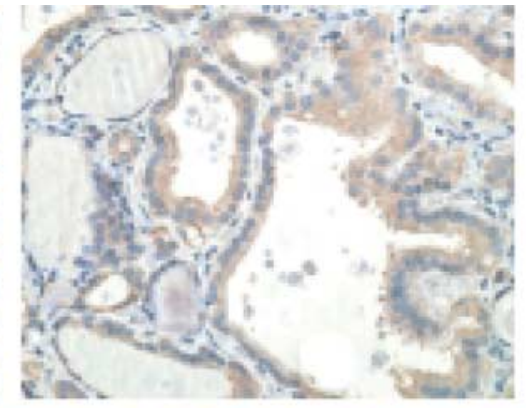
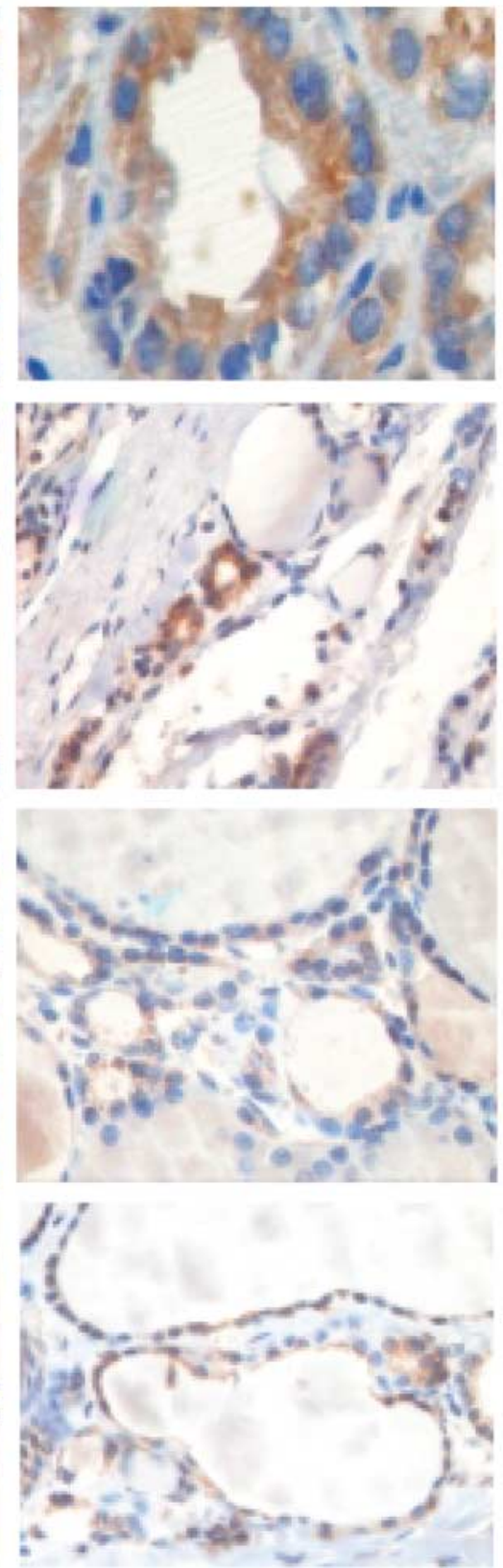

Figure 2 (continued)
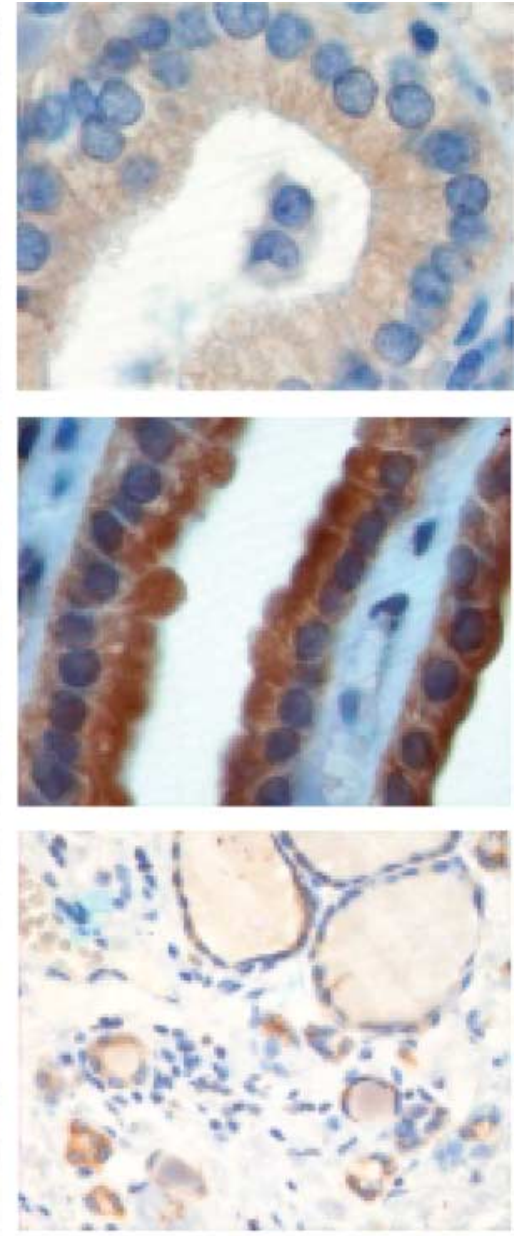

D

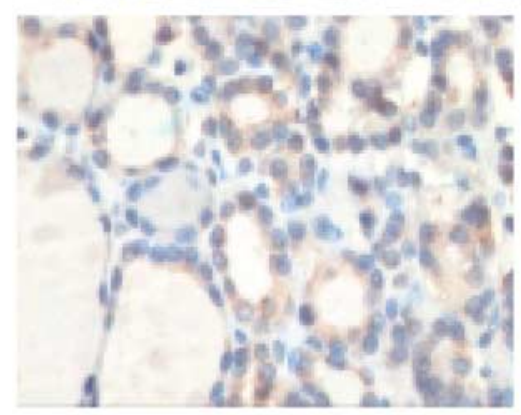

$\mathbf{E}$
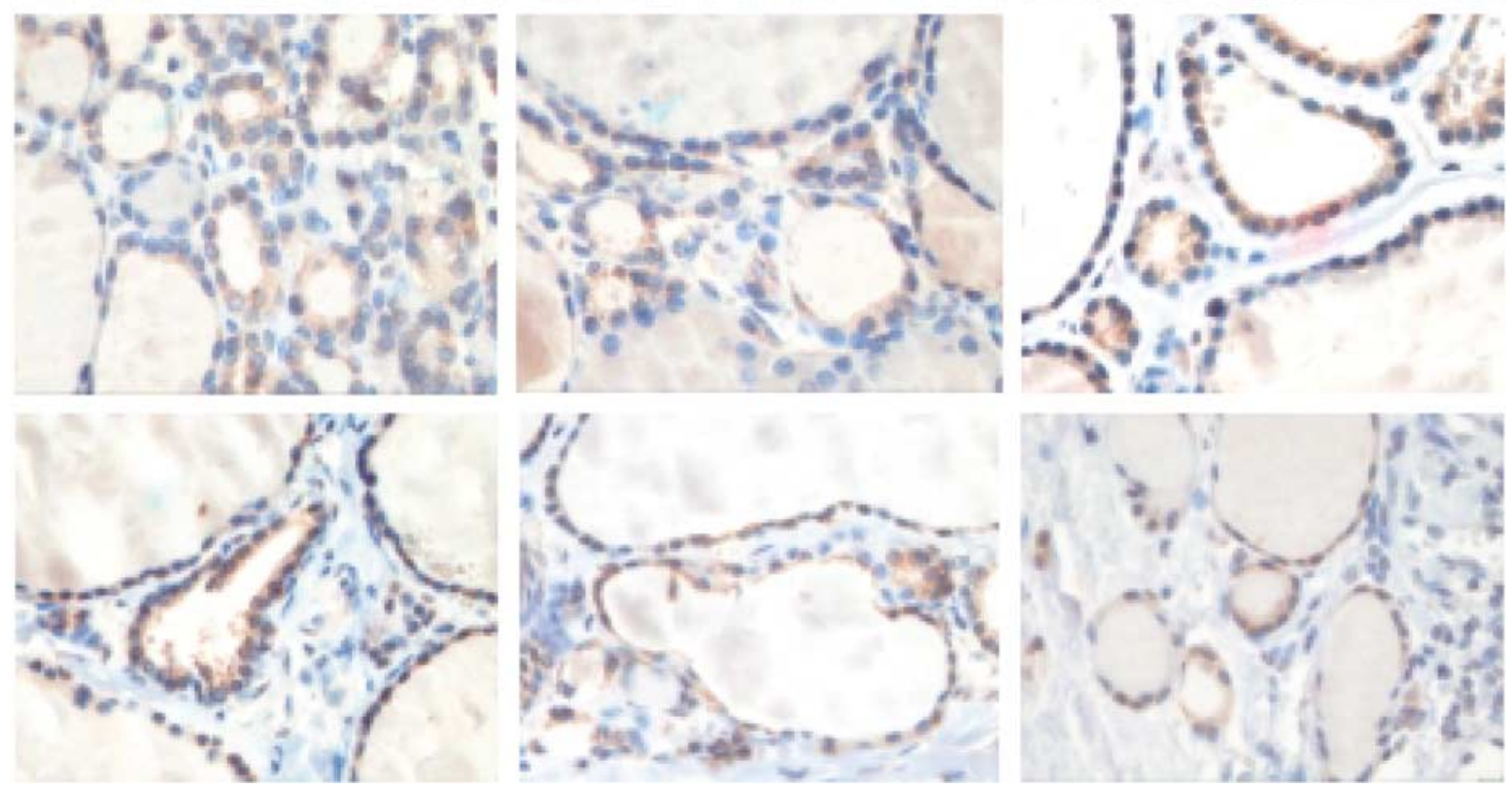

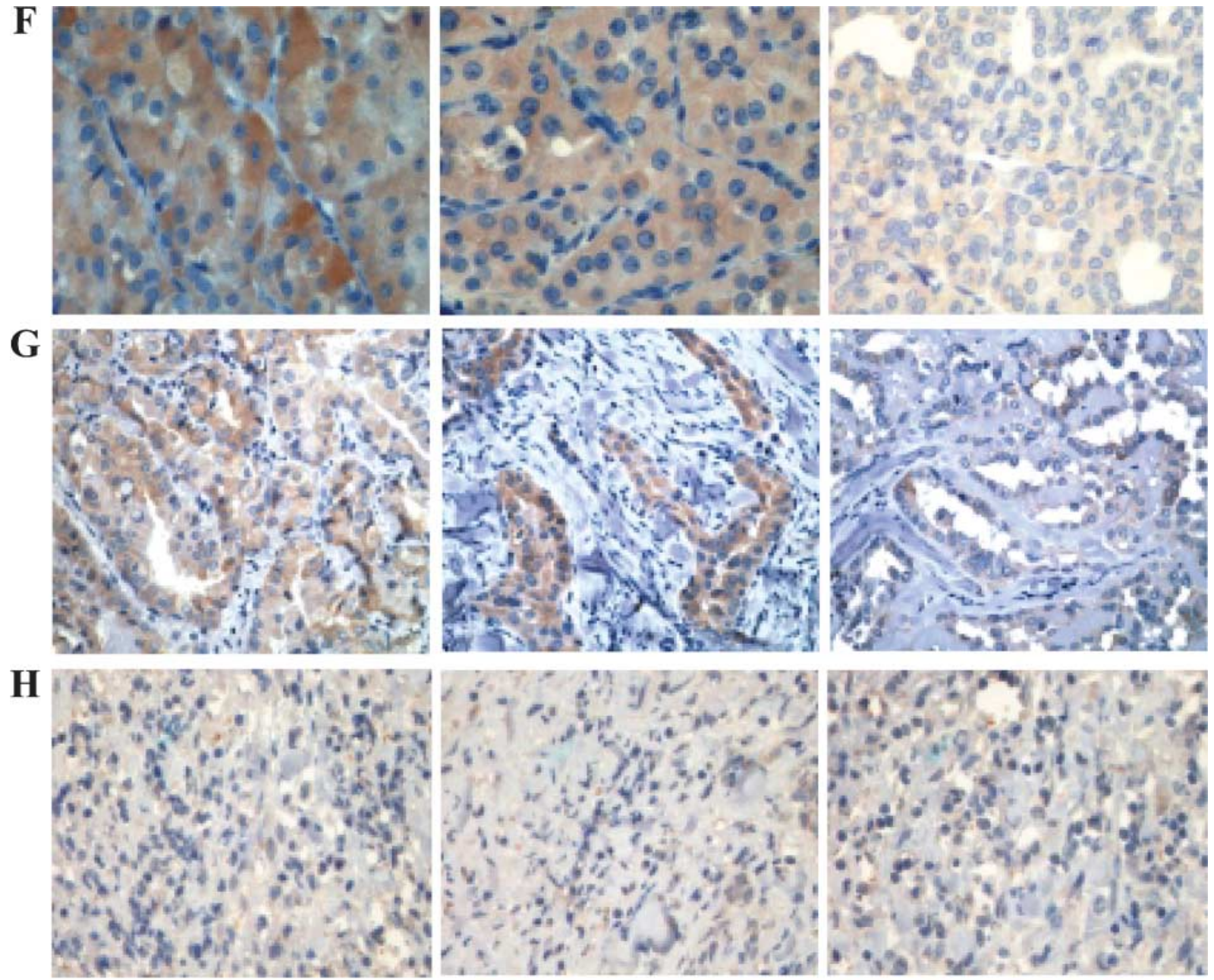

I
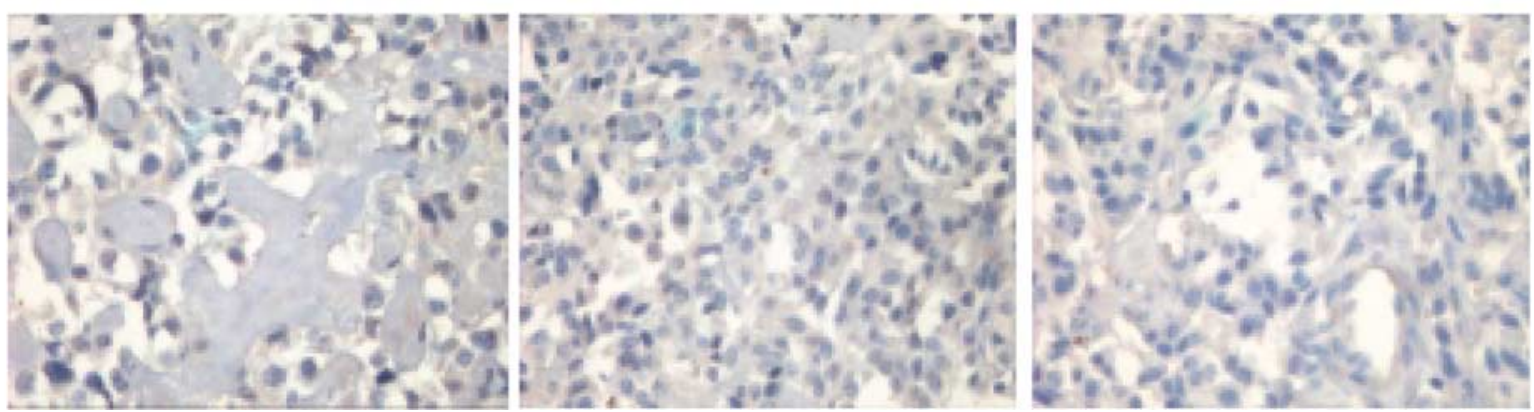

Figure 2 Immunodetection of DEHAL1 protein expression in different thyroid pathologies. (A) Graves' disease, (B) toxic thyroid nodule, (C) surrounding tissue of toxic thyroid nodule, (D) cold thyroid nodule, (E) surrounding tissue of cold thyroid nodule, (F) follicular thyroid carcinoma, $(\mathrm{G})$ papillary thyroid carcinoma, $(\mathrm{H})$ anaplastic thyroid carcinoma, (I) medullary thyroid carcinoma $(200 \times$ magnification).

different thyroid functional and/or differentiation states, we performed mRNA analyses of DEHAL1 and its isoform DEHAL1B and studied DEHAL1 protein expression by immunohistochemistry in a series of hyper- and hypofunctioning thyroid nodules, Graves' disease thyroids, normal thyroid tissues and different thyroid cancers.
DEHAL1 expression was altered in differentially functioning thyroid pathologies, whereby changes in mRNA and protein expression levels were largely concordant. The highest DEHAL1 expression levels were detected in GD samples and toxic thyroid nodules, which is in agreement with stimulation of thyroid hormone production and as a 'by-process' of 
A

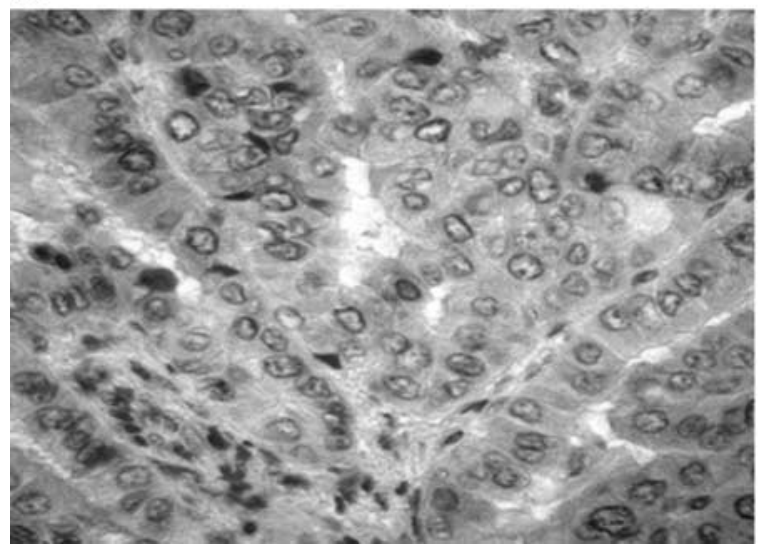

B

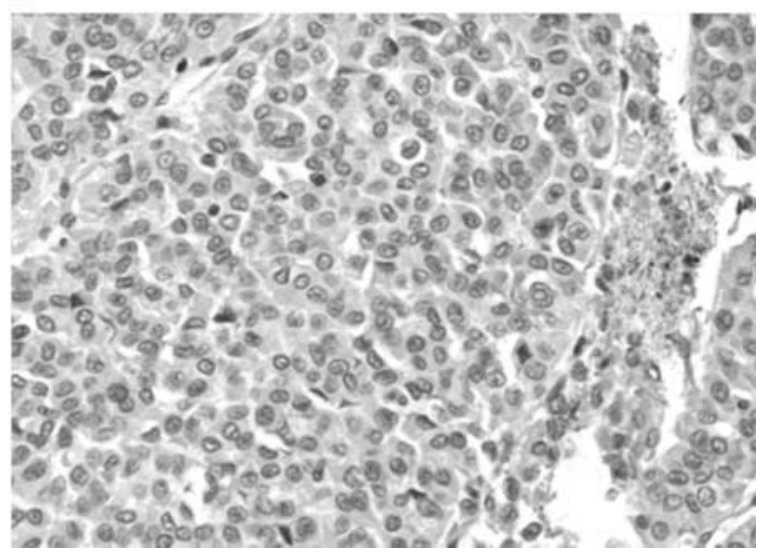

Figure 3 Localisation of DEHAL1 in papillary thyroid carcinomas. In PTCs with a conventional papillary appearance (A), diffuse and cytoplasmatic $D E H A L 1$ is apparent, whereas in partially differentiated papillary thyroid carcinoma (B), DEHAL1 protein expression is absent.

increased MIT/DIT deiodination. Thus, while upregulation of NIS in the hyperfunctional lesions will allow efficient iodine trapping, upregulation of DEHAL1 will ensure efficient iodine recycling. Both mechanisms contribute towards a highly effective generation of thyroid hormones in thyrotoxicosis. Furthermore, the localisation of DEHAL1 protein in GD thyroids and TTNs towards the apical pole is in line with in vitro data suggesting that DEHAL action takes place in close proximity to endoluminal TG uptake and proteolysis (4).

An increased, albeit much weaker (compared with the hyperfunctional states) DEHAL1 mRNA expression was detected in CTN compared with their ST. Again, this could be linked to altered thyroid hormone synthesis, which is ineffective in CTN, primarily as a consequence of impaired iodide trapping $(7,10,11)$. It is noteworthy that an increased expression of other components of the thyroid-hormone synthesising apparatus, e.g. TPO and thyroid oxidase, has recently been observed by differential proteome analysis of cold thyroid nodules (12). In addition, CTN and ST (as opposed to hyperfunctional lesions) exhibited a focal, rather than uniform DEHAL1 expression pattern. DEHAL1 staining was most prominent in small follicles, which are believed to be more actively involved in thyroid hormone turnover than the large colloid storing follicles $(13,14)$.

Additionally, we tried to elucidate the value of DEHAL1 as a marker of thyroid differentiation. Prominent DEHAL1 protein expression was observed in follicular thyroid carcinomas; however, in these cancers, DEHAL1 expression was diffuse and there was no predominance of DEHAL1 expression at the apical cell region. Diffuse cytoplasmatic localisation was also observed in papillary thyroid cancers, albeit with an overall weaker DEHAL1 expression. In contrast, in partially differentiated cancers and undifferentiated thyroid cancers, protein staining was very faint or mostly absent (Figs $4 \mathrm{~A}$ and B). A similar pattern in tumour-specific DEHAL1 expression was also apparent on the mRNA level. These findings suggest a loss of DEHAL1 with ongoing thyroid cell dedifferentiation.

Furthermore, we found a significantly higher expression of DEHAL1B variants in FTC and CTN. To date, there are no consistent data on the physiological relevance of the DEHAL1B isoform. Gnidehou et al. recently have cloned and characterised another DEHAL1 isoform termed DEHAL1C (3). They show that the mRNA expression of DEHAL1B and DEHAL1C variants were lower in thyrocytes compared with DEHAL1 and suggested that this is linked to a more rapid proteosomal degradation. However, the functional consequences regarding thyroid hormone metabolism are still unknown.

In summary, our study provides first evidence that DEHAL1 might be a marker of differentiated thyroid function and that upregulation and predominant apical DEHAL1 localisation occurs in the hyperfunctional states, while thyroid malignancy is associated with diffuse cytoplasmatic localisation (differentiated FTC/PTC) or complete loss of DEHAL1 expression (partially differentiated thyroid cancers and ATC). To follow up on the hypothesis of a functional relevance of altered intracellular DEHAL1 localisation, further studies on the molecular regulation of DEHAL1 expression and its isoforms are mandatory and will be crucial for the understanding of the physiological and a putative pathophysiological role of DEHAL1 in the thyroid. 


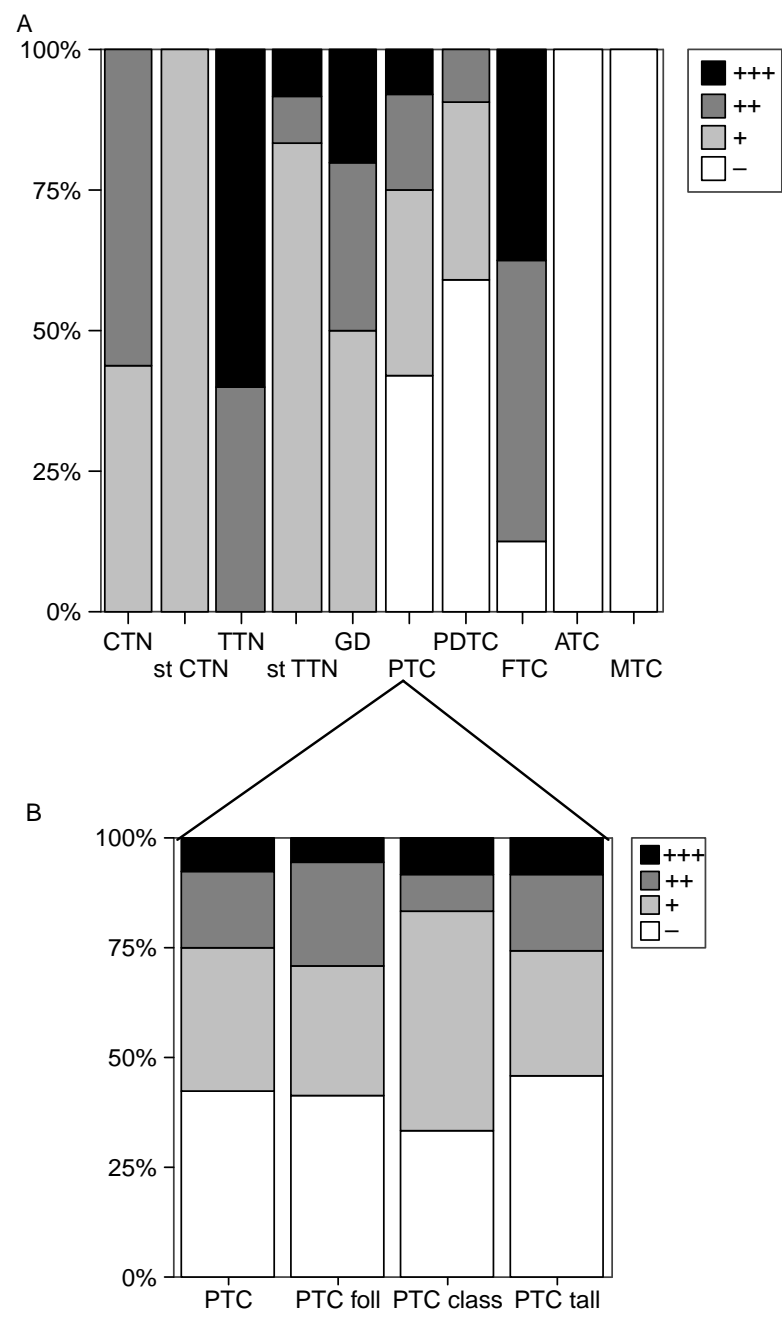

Figure 4 Semiquantitative analysis of DEHAL 1 protein expression in thyroid pathologies. DEHAL1 staining was assessed by determining the percentage of positively stained thyrocytes/six randomly selected sections/slide (200× magnification, duplicates). The degree of staining was quantified as follows: - , no staining; ,$+<30 \%$ staining;,$++ 30-60 \%$ staining;,$+++>60 \%$ staining. (A) Benign and malignant thyroid disease: Graves' disease (GD; $n=5$ ), toxic thyroid nodule (TTN; $n=11$ ), surrounding tissue of toxic thyroid nodule (stTTN; $n=11$ ), cold thyroid nodule (CTN; $n=16$ ), surrounding tissue of cold thyroid nodule (stCTN; $n=16$ ), follicular thyroid carcinoma (FTC; $n=8$ ), papillary thyroid carcinoma (PTC; $n=64)$, partially differentiated thyroid carcinoma (PDTC; $n=22$ ), undifferentiated (anaplastic) thyroid carcinoma (ATC; $n=6)$, medullary thyroid carcinoma (MTC; $n=5$ ). (B) Subgroup analysis for papillary thyroid carcinoma (PTC; $n=64)$ : follicular variant PTC $(n=17)$, conventional (classic) PTC $(n=12)$ and tall cell PTC $(n=34)$.

\section{Acknowledgements}

We thank Monika Gutknecht for excellent technical help. We are grateful to Prof. Lamesch, Department of Surgery, University of Leipzig and Dr Mühl, Department of Surgery, Wurzen for the supply of thyroid tissue samples. This study was supported by the D F G (Emmy Noether Nachwuchsgruppe to Dagmar Führer, FU 356/1-2).

\section{References}

1 Roche J, Michel R, Michel O \& Lissitzky S. Enzymatic dehalogenation of iodotyrosine by thyroid tissue; on its physiological role. Biochimica et Biophysica Acta 19529 161-169.

2 Rosenberg IN \& Goswami A. Purification and characterization of a flavoprotein from bovine thyroid with iodotyrosine deiodinase activity. Journal of Biological Chemistry 1979254 $12318-12325$.

3 Gnidehou S, Lacroix L, Sezan A, Ohayon R, Noel-Hudson MS, Morand S, Francon J, Courtin F, Virion A \& Dupuy C. Cloning and characterization of a novel isoform of iodotyrosine dehalogenase 1 (DEHAL1) DEHAL1C from human thyroid: comparisons with DEHAL1 and DEHAL1B. Thyroid 200616 715-724.

4 Gnidehou S, Caillou B, Talbot M, Ohayon R, Kaniewski J, Noel-Hudson MS, Morand S, Agnangji D, Sezan A, Courtin F, Virion A \& Dupuy C. Iodotyrosine dehalogenase 1 (DEHAL1) is a transmembrane protein involved in the recycling of iodide close to the thyroglobulin iodination site. FASEB Journal 200418 1574-1576.

5 Moreno JC. Identification of novel genes involved in congenital hypothyroidism using serial analysis of gene expression. Hormone Research 200360 96-102.

6 Krohn K, Fuhrer D, Bayer Y, Eszlinger M, Brauer V, Neumann S \& Paschke R. Molecular pathogenesis of euthyroid and toxic multinodular goiter. Endocrine Reviews 200526 504-524.

7 Neumann S, Schuchardt K, Reske A, Reske A, Emmrich P \& Paschke R. Lack of correlation for sodium iodide symporter mRNA and protein expression and analysis of sodium iodide symporter promoter methylation in benign cold thyroid nodules. Thyroid 200414 99-111.

8 Eszlinger M, Krohn K, Berger K, Lauter J, Kropf S, Beck M, Fuhrer D \& Paschke R. Gene expression analysis reveals evidence for increased expression of cell cycle-associated genes and Gq-protein-protein kinase C signaling in cold thyroid nodules. Journal of Clinical Endocrinology and Metabolism 200590 1163-1170.

9 Fuhrer D, Eszlinger M, Karger S, Krause K, Engelhardt C, Hasenclever D, Dralle H \& Paschke R. Evaluation of insulin-like growth factor II, cyclooxygenase-2, ets-1 and thyroid-specific thyroglobulin mRNA expression in benign and malignant thyroid tumours. European Journal of Endocrinology $2005 \mathbf{1 5 2}$ 785-790.

10 Trouttet-Masson S, Selmi-Ruby S, Bernier-Valentin F, Porra V, BergerDutrieux N, Decaussin M, Peix JL, Perrin A, Bournaud C, Orgiazzi J, Borson-Chazot F, Franc B \& Rousset B. Evidence for transcriptional and posttranscriptional alterations of the sodium/iodide symporter expression in hypofunctioning benign and malignant thyroid tumors. American Journal of Pathology 2004165 25-34.

11 Dohan O, De la Vieja A, Paroder V, Riedel C, Artani M, Reed M, Ginter CS \& Carrasco N. The sodium/iodide symporter (NIS): characterization, regulation, and medical significance. Endocrine Reviews 200324 48-77.

12 Krause K, Karger S, Schierhorn A, Poncin S, Many MC \& Fuhrer D. Proteomics of cold thyroid nodules. Endocrinology e-pub ahead of print.

13 Dumont JE, Maenhaut C, Lamy F, Pirson I, Clement S \& Roger PP. Growth and proliferation of the thyroid cell in normal physiology and in disease. Annals of Endocrinology 200364 10-11.

14 Gerard AC, Many MC, Daumerie C, Costagliola S, Miot F, DeVijlder JJ, Colin IM \& Denef JF. Structural changes in the angiofollicular units between active and hypofunctioning follicles align with differences in the epithelial expression of newly discovered proteins involved in iodine transport and organification. Journal of Clinical Endocrinology and Metabolism 200287 1291-1299.

Received 4 October 2006

Accepted 18 December 2006 